\title{
Befolkningens tilfredshet med helsetjenesten og legers tilfredshet med arbeidssituasjonen
}

\author{
Sammendrag \\ Bakgrunn. Vi ønsket å sammenlikne \\ utviklingen i befolkningens tilfredshet \\ med helsetilbudet med utviklingen \\ i legers tilfredshet med arbeidssitua- \\ sjonen.
}

Materiale og metode. Data om legers tilfredshet med arbeidssituasjonen ble hentet fra referansepanelet til Legeforeningens forskningsinstitutt for 1994 , 2000, 2002 og 2006. Data om befolkningens tilfredshet med helsetilbudet ble hentet fra TNS Gallups kommuneundersøkelser for 1995-2000, 2003 og 2005 for allmennlegetjenesten og for 1999, 2000 og 2003 for sykehustilbudet. Data om befolkningens vurdering av ressursbruk ble hentet fra den norske delen av International Social Survey Program. Tidsserier for legetilfredshet ble laget ved å beregne endring i jobbtilfredshet mellom to påfølgende undersøkelser og for befolkningens tilfredshet ved å beregne årlige regresjonsjusterte gjennomsnitt.

Resultater. På en skala fra 10 til 70 $\varnothing k$ te sykehuslegers jobbtilfredshet fra 50,2 i 1994 til 52,3 i 2006. Allmennlegers jobbtilfredshet økte fra 52,5 til 55,5 i samme tidsrom. Fra 1995 til 2005 $\varnothing$ kte befolkningens tilfredshet med allmennlegetjenesten fra 4,43 til 4,54 og fra 1999-2003 økte befolkningens tilfredshet med sykehustilbudet fra 4,23 til 4,47 (på skala 1-6). Befolkningsandelen som mener det brukes for lite offentlige ressurser på helsetjenesten, økte fra 82,7 til 85,2 i perioden 1990-2006.

Fortolkning. Vi fant ikke at hensynet til pasientene har måtte vike for helsepersonellets interesser eller vice versa. Et stor og økende andel av befolkningen mener at det brukes for lite ressurser på helsetjenester.

\section{Fredrik Carlsen}

fredrik.carlsen@svt.ntnu.no

Institutt for samfunnsøkonomi

Norges teknisk-naturvitenskapelige universitet 7491 Trondheim

\section{Berit Bringedal}

Legeforeningens forskningsinstitutt og

Institutt for helseledelse og helseøkonomi Universitetet i Oslo

Både spørreundersøkelser om befolkningens tilfredshet med helsevesenet og om helsepersonalets tilfredshet med arbeidssituasjonen gir verdifull informasjon om tilstanden i helsevesenet. Data om befolkningens oppfatninger forteller hvordan brukerne vurderer behandlingstilbudet, mens data om jobbtilfredshet gir informasjon om risikofaktorer for stress, utbrenthet og rekrutteringsproblemer (1). Det foreligger en rekke norske undersøkelser om befolkningens tilfredshet med sykehustilbudet (2-3) og allmennlegetjenesten (4-6) og om legers tilfredshet med arbeidssituasjonen (1,7-11). Imidlertid kjenner vi ikke til arbeider som ser befolkningens og helsepersonalets oppfatninger i sammenheng.

Det er interessant å sammenlikne befolkningens og helsepersonalets vurderinger, fordi man da făr vite noe om hvorvidt utviklingen $\mathrm{i}$ helsevesenet har vært balansert. Med balansert menes at organisering, finansiering og styring av helsevesenet tar hensyn til både pasientene og dem som arbeider $\mathrm{i}$ helsevesenet. Hvis f.eks. trendanalyser viser at befolkningen er blitt mer fornøyd mens helsepersonalet er blitt mindre fornøyd, er det grunn til å spørre om arbeidet med å forbedre behandlingstilbudet har hatt en slagside i disfavør av de ansatte, noe som på sikt kan gå utover pasientene.

I denne studien har vi beregnet trender i befolkningens tilfredshet med helsevesenet og legers tilfredshet med arbeidssituasjonen i perioden 1994-2006.

\section{Materiale og metode \\ Legenes oppfatninger}

Data om legers tilfredshet med sin arbeidssituasjon ble hentet fra referansepanelet, et utvalg leger etablert av Legeforeningens forskningsinstitutt i 1993. Ved første gangs undersøkelse (1994) besto panelet av ca. 1300 leger. Panelet ble siden komplettert og består i dag av ca. 1600 leger. Med 1-2 års mellomrom mottar medlemmene av panelet et spørreskjema. Spørsmålene om tilfredshet med jobbsituasjonen er basert på måleinstrumentet Job Satisfaction Scale (12) og ble inkludert i fem av undersøkelsene (i 1994, 2000, 2002, 2004 og 2006). I disse undersøkelsene hadde spørreskjemaet ti spørsmål om følgende aspekter ved arbeidsforholdene: ansvar, variasjon, forholdet til kolleger, fysisk arbeidsmiljø, utfoldelsesmuligheter, samlet jobbtilfredsstillelse, valgmuligheter, anerkjennelse, lønn og arbeidstid. På hvert spørsmål angis et heltall fra 1 til 7, der 1 betyr svært misfornøyd og 7 betyr svært fornøyd. Vårt mål på jobbtilfredshet er summen av svarene på alle spørsmålene. Maksimumsverdien er følgelig 70, mens minimumsverdien er 10. Da vi ønsket å skille mellom leger som arbeider ved sykehus og allmennleger, så vi bort fra 2004, da informasjon om hovedstilling manglet for dette året.

For å beregne utviklingen i jobbtilfredshet mellom to undersøkelser baserte vi oss på leger med samme hovedstilling (sykehuslege eller allmennlege) i de to undersøkelsene og som svarte på spørsmålene om jobbtilfredshet begge ganger. Dette ga oss utvalg på i underkant av 400 sykehusleger og om lag 200 allmennleger for hvert par av undersøkelser. For disse legene ble gjennomsnittlig endring i jobbtilfredshet fra den første undersøkelsen til den neste beregnet. Dette ga et anslag på endring i jobbtilfredshet fra 1994 til 2000, fra 2000 til 2002 og fra 2002 til 2006. Til slutt tok vi utgangspunkt i gjennomsnittlig rapportert jobbtilfredshet $\mathrm{i}$ 1994 og la til endringene for 1994-2000, 2000-02 og 2002-06. Dette ga oss tidsserier for henholdsvis sykehusleger og allmennleger.

\section{Befolkningens tilfredshet}

Data om befolkningens tilfredshet med sykehus- og allmennlegetilbudet ble hentet fra

\section{Hovedbudskap}

- Leger og befolkningen er stort sett enige om utviklingen i helsetjenesten

- Både leger og befolkningen er mer tilfredse med allmennlegetjenesten enn med sykehustilbudet

- Både leger og befolkningen er blitt mer tilfredse de siste årene

- Befolkningen ønsker å bruke mer penger på det offentlige helsevesenet 


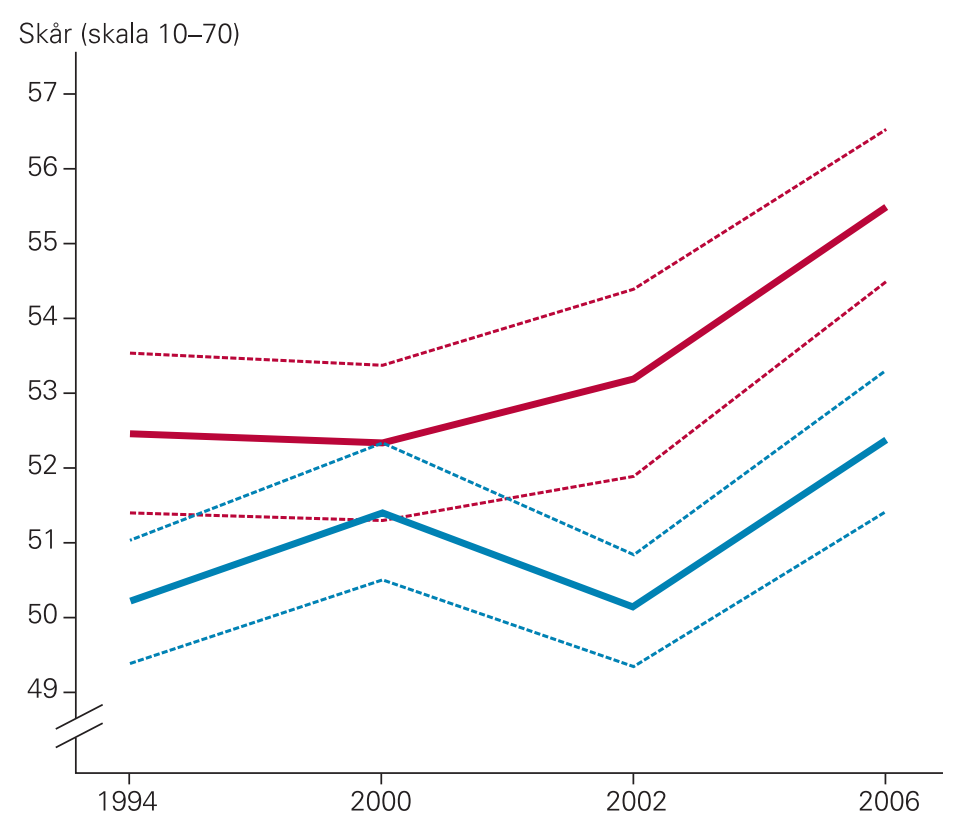

Figur 1 Sykehuslegenes og allmennlegenes jobbtilfredshet 1994-2006, basert på referansepanelet til Legeforeningens forskningsinstitutt. Det vises gjennomsnittlig tilfredshet på en skala fra 10 til 70 for sykehusleger (blå kurve) og allmennleger (rød kurve), med $95 \%$ konfidensintervaller (stiplete linjer)
TNS Gallups landsomfattende kommuneundersøkelser. De fleste år siden midten av 1990-årene har TNS Gallup gjennomført spørreundersøkelser der respondentene vurderer en rekke aspekter ved bostedskommunen, herunder allmennlegetjenesten. Noen av undersøkelsene inneholder også spørsmål om sykehustilbudet i bostedsfylket. Et tilfeldig utvalg på $30000-50000$ personer mottar spørreskjemaet, og svarprosenten er ca. $50 \%$. Spørsmålene om allmennlegetjenesten har høy svarprosent (80-90\%), mens svarprosenten på spørsmålene om sykehustilbudet er betydelig lavere (40-50\%).
Vi baserte vår analyse på fire spørsmål som var tilnærmet like for sykehus og allmennlegetjenesten, og som har vært uforandret gjennom flere år: Hvor tilfreds man er med ventetid, informasjon, personalets faglige dyktighet og behandlingsresultatet. På hvert spørsmål angis et heltall mellom $1 \mathrm{og}$ 6 , der 6 betyr mest tilfreds og 1 betyr minst tilfreds. Respondentene ble bedt om å basere sine vurderinger på personlige erfaringer dersom de hadde hatt kontakt med sykehus/ allmennlege og ellers oppgi sine generelle inntrykk.

Som mål på en respondents generelle til-

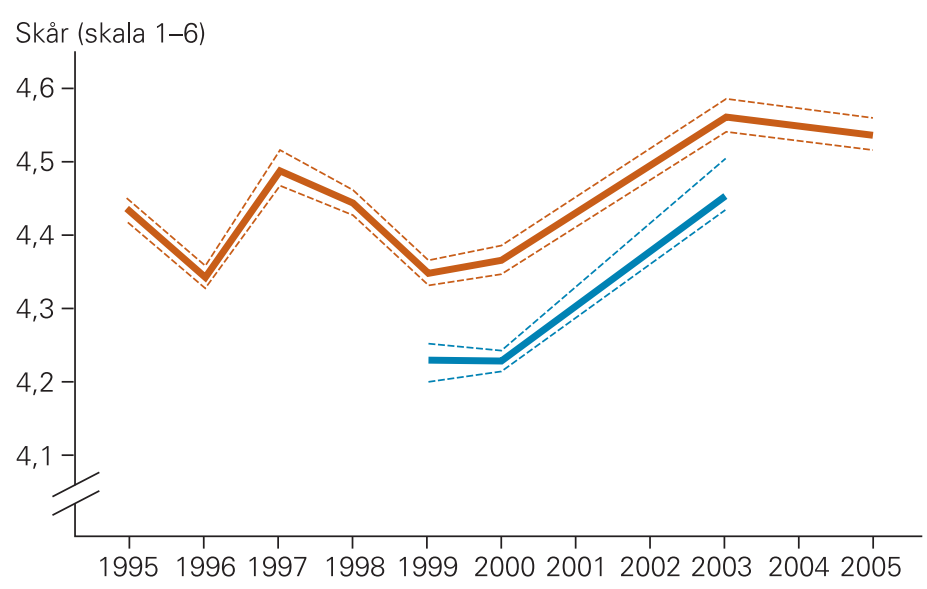

Figur 2 Befolkningens tilfredshet med helsetjenesten 1995-2005 på en skala fra 1 til 6, basert på TNS Gallups kommuneundersøkelser. Det vises regresjonsjustert gjennomsnittlig tilfredshet for sykehustilbudet (blå kurve) og allmennlegetjenesten (rød kurve), med $95 \%$ konfidensintervaller (stiplete linjer) fredshet med henholdsvis sykehustilbudet og allmennlegetjenesten brukte vi gjennomsnittet av svarene på de fire spørsmålene. For allmennlegetjenesten hadde vi data fra åtte undersøkelser i perioden 1995-2005, mens vi hadde data om tilfredshet med sykehustilbudet fra tre undersøkelser i perioden 1999-2003. Totalt antall respondenter var henholdsvis 96334 (allmennlegetjenesten) og 18957 (sykehus).

Vi kontrollerte for respondentenes kjønn, alder og utdanning for å ta hensyn til endringen i utvalgets alders- og kjønnsfordeling samt utdanningsnivå mellom undersøkelser ved å beregne regresjonsjusterte gjennomsnitt. For henholdsvis sykehustilbudet og allmennlegetjenesten ble én regresjon for respondentene i alle undersøkelsene estimert ved hjelp av minste kvadraters metode. Regresjonen forklarer respondentenes tilfredshet som en funksjon av personkarakteristika og dummyvariabler for hver undersøkelse. Koeffisienten til dummyvariablene kan tolkes som gjennomsnittlig tilfredshet korrigert for forskjeller i alder, kjønn og utdanningsnivå.

\section{Befolkningens vurdering av ressursbruk} International Social Survey Program (ISSP) er en internasjonal organisasjon som koordinerer årlige nasjonale spørreundersøkelser, hovedsakelig innenfor sosiologiske og statsvitenskapelige problemstillinger. Norsk samfunnsvitenskapelig datatjeneste (NSD) er ansvarlig for den norske delen av undersøkelsen. Dataene som de har tilrettelagt, er offentlige og finnes på deres nettside (www.nsd.uib).

Vi brukte informasjon fra undersøkelsene om befolkningens vurdering av hvor mye det offentlige bør bruke på helse. Dette er del av de undersøkelsene som ble gjennomført i 1990, 1996 og 2006. Spørsmålsformuleringen lød: «I listen nedenfor finner du ulike områder der det offentlige har utgifter. Angi om du ønsker at det offentlige skal bruke mer eller mindre på hvert enkelt område. Husk at hvis du svarer «mye mer», kan det bety skatteøkning for å bekoste det.» Svaralternativene dekket området fra «mye mer» til «mye mindre».

Samtlige analyser er gjort ved hjelp av statistikkprogrammet STATA, versjon 9. For å teste hvorvidt endringer i legers jobbtilfredshet er statistisk signifikant, har vi brukt ANOVA for gjentatte observasjoner. F-tester som sammenlikner koeffisientene til dummyvariablene er brukt til å teste om endringer i befolkningens tilfredshet er statistisk signifikant.

\section{Resultater}

Sykehuslegenes jobbtilfredshet var stabil over hele tidsperioden, med kun små svingninger i gjennomsnittlig tilfredshet (fig 1). Fra 1994 til 2006 steg jobbtilfredsheten fra 50,2 til 52,3, hvilket utgjorde kun 3,5\% av variasjonsbredden (differansen mellom 
høyest og lavest mulige verdi). Endringene mellom år var imidlertid statistisk signifikant (1994-2000: $\mathrm{p}=0,01 ; 2000-02: \mathrm{p}=$ 0,002; 2002-06: $\mathrm{p}<0,0001)$.

Allmennlegenes jobbtilfredshet var stabil fra 1994 til 2002 og steg noe til 2006. I hele perioden 1994-2006 økte allmennlegenes jobbtilfredshet fra 52,5 til 55,5. Endringen utgjorde $5 \%$ av variasjonsbredden. Endringene fra 1994 til 2002 var ikke statistisk signifikant, mens endringen fra 2002 til 2006 var signifikant $(\mathrm{p}<0,0001)$. Allmennlegenes jobbtilfredshet lå hele tiden noe over sykehuslegenes jobbtilfredshet. For begge gruppers vedkommende var 2006-nivået noe høyere enn ved tidligere undersøkelser.

Befolkningens tilfredshet med sykehustilbudet var stabil fra 1999 til 2000 og noe høyere i 2003 (fig 2). Befolkningens tilfredshet med allmennlegetjenesten var uforandret fra 1995 til 2000 og økte noe til 2003 og 2005. Som følge av det store antall deltakere i TNS Gallups undersøkelser var endringene $\mathrm{i}$ befolkningens tilfredshet med sykehustilbudet og allmennlegetjenesten statistisk signifikant, med $\mathrm{p}<0,0001$ de fleste år.

I perioden 1990-2006 økte andelen i befolkningen som mente at det bør brukes mer eller mye mer ressurser på offentlige helsetjenester, fra $82,7 \%$ til $85,2 \%$ (e-fig 3 ).

\section{Diskusjon}

Det er stor grad av sammenfall mellom legenes og befolkningens vurderinger. Gruppene var enige om at situasjonen $i$ allmennlegetjenesten var noe bedre enn i sykehussektoren, begge grupper mente at situasjonen både $\mathrm{i}$ sykehussektoren og i allmennlegetjenesten endret seg lite i 1990-årene, mens begge grupper mente at situasjonen var blitt noe bedre de siste årene. Vi fant følgelig ingen holdepunkter for at hensynet til pasientene har måttet vike for helsepersonalets interesser eller vice versa.

Når det gjelder de to store helsereformene de siste årene, nemlig sykehusreformen og fastlegereformen, syntes legene og befolkningen å være enige om at utviklingen har gått $\mathrm{i}$ riktig retning $\mathrm{i}$ tiden etter reformene. Denne konklusjonen er konsistent med tidligere undersøkelser av legers og brukeres oppfatning av fastlegereformen $(4-6,10)$ og befolkningens oppfatning av sykehusreformen (3).

Interessant nok har økt tilfredshet gått hånd i hånd med sterkere ønske om å satse på helsevesenet. Et stort flertall mente at det offentlige skal øke utgiftene til helsevesenet. Andelen som ønsker dette, har steget noe over tid. Våre analyser tyder på at økningen i andelen som ønsker sterkere satsing, ikke skyldes at befolkningen er blitt mer misfornøyd med helsetilbudet, men heller kan tolkes som et uttrykk for sterk og tiltakende betalingsvilje for et godt offentlig helsevesen.

En viktig metodisk utfordring ved analyser av subjektive vurderinger er at folks til- fredshet ikke bare avhenger av objektive faktorer, men også av personlighetstrekk. Noen er generelt mer fornøyde enn andre, uavhengig av den faktiske situasjonen (13). Hvis en undersøkelse gjentas med et nytt utvalg respondenter, kan man ikke vite sikkert om endringer i folks oppfatninger skyldes at det som vurderes har endret seg, eller at forskjellige personer er spurt i de to undersøkelsene. Referansepanelet gjør det mulig å komme rundt dette problemet, fordi mange leger har deltatt $i$ to eller flere undersøkelser. Dermed påvirkes resultatene lite av respondentenes personlighetstrekk. På den annen side mister vi leger som slutter i sykehussektoren eller allmennlegetjenesten i løpet av perioden mellom undersøkelsene. Hvis leger som skifter jobb, generelt er mindre fornøyd med sin arbeidssituasjon enn andre leger (når det kontrolleres for initial tilfredshet), vil metoden overvurdere endringen $i$ jobbtilfredshet mellom undersøkelsene. Dette medfører at vi kan feilvurdere tendensene i legers tilfredshet. Imidlertid er det lite sannsynlig at endringer i trendene påvirkes særlig. Konklusjonen om at leger vurderer utviklingen etter århundreskiftet som mer positiv enn utviklingen i 1990-årene, er antakelig robust.

Dette understøttes også av at kvaliteten på datamaterialet er god. Referansepanelet er et representativt utvalg av norske leger, og svarprosenten ligger mellom 70 og 80 . Vi sjekket utvalget mot populasjonen på enkelte indikatorer og fant godt samsvar både $\mathrm{i}$ andel fastleger og fordeling mellom kvinner og menn. I 2002 var $31 \%$ av norske leger kvinner (14). Andelen kvinner i referansepanelet var samme år $31 \% .24 \%$ av legene var allmennleger i 2003 (14), mens $29 \%$ av referansepanelet oppga at de var fastleger $i$ 2002 og $24 \%$ i 2006.

Som beskrevet i presentasjonen av materialet, har vi vektet de ti indikatorene på jobbtilfredshet likt. Dette gjelder også for verdiene på de ti dimensjonene; fra svært misfornøyd til svært fornøyd. Dette er ikke selvsagt, man kan for eksempel ha teoretiske grunner til å vekte en eller flere indikatorer mer enn de andre eller betrakte ekstremverdier (svært-verdier) annerledes enn middelsverdier. Vi anser det imidlertid som en rimelig antakelse at en uvektet sum kan gi et generelt bilde av tilfredshet. Det er mer problematisk å skille ut enkeltfaktorer og anta at nettopp denne faktoren gir et bedre uttrykk for jobbtilfredshet. En nærmere diskusjon av dette er interessant, men går utenfor rammen for denne artikkelen.

Mens referansepanelet sier hvordan en leges oppfatning har endret seg mellom to undersøkelser, gir ikke TNS Gallups kommuneundersøkelser informasjon om endringer $\mathrm{i}$ en og samme persons vurderinger. Få respondenter vil være felles for to av TNS Gallups undersøkelser, og disse respondentenes identitet er ukjent. For å kunne si noe om utviklingen i befolkningens tilfredshet over tid, var vi henvist til å sammenlikne ulike personers vurderinger. Dermed risikerte vi at endringer i uttrykt tilfredshet fra en undersøkelse til neste delvis skyldes at det var forskjellige personer som deltok.

Et potensielt problem ved undersøkelser av jobbtilfredshet eller tilfredshet med tjenestetilbudet er at rapportert tilfredshet reflekterer forholdet mellom situasjonen slik den oppfattes og situasjonen slik den forventes å være. Hvis forventningene øker, kan rapportert tilfredshet gå ned selv om situasjonen objektivt sett ikke er blitt verre. Stigende forventninger kan derfor bidra til at forbedringer undervurderes. Men siden vi finner at både leger og befolkningen er blitt mer tilfredse over tid, kan ikke stigende forventninger forklare denne konklusjonen.

Oppgitte interessekonflikter: Ingen

e-fig 3 finnes i artikkelen på www.tidsskriftet.no

\section{Litteratur}

. Finset KB, Gude T, Hem E et al. Which young physicians are satisfied with their work? A prospective nationwide study in Norway. BMC Med Educ 2005 5: 19

2. Oltedal S, Garratt A, Helgeland J. Pasienters erfaringer med døgnenheter ved somatiske sykehus. Resultater fra en nasjonal undersøkelse i 2006. Rapport nr. 1/2007. Oslo: Nasjonalt kunnskapssenter for helsetjenesten, 2007.

3. Carlsen F, Grytten J, Skau I. Befolkningens tilfredshet med sykehusene før og etter sykehus reformen. Tidsskr Nor Lægeforen 2005; 125: 2034-7.

4. Finnvold JE, Svalund J, Paulsen B. Etter innføring av fastlegeordning - brukervurderinger av allmennlegetjenesten. Rapport nr. 1/2005. Oslo: Statistisk sentralbyrå, 2005.

5. Lian O, Wilsgaard T. Pasienterfaringer i primærlegetjenesten før og etter fastlegeordningen. Tidsskr Nor Lægeforen 2004: 124: 655-8.

6. Grytten J, Skau I, Carlsen F. Brukertilfredshet i allmennlegetjenesten $f ø r$ og etter fastlegereformen. Tidsskr Nor Lægeforen 2004; 124: 652-4.

7. Nylenna M, Gulbrandsen P, Førde R et al. Unhappy doctors? A longitudinal study of life and job satisfaction among Norwegian doctors 1994-2002. BMC Health Serv Res 2005; 5: 44.

8. Nylenna M, Gulbrandsen P. Førde R et al. Job satisfaction among Norwegian general practitioners. Scand J Prim Health Care 2005: 23: 198-202.

. Hetlevik $\emptyset$. Hunskår S. Listelengde, arbeidstid, ventetid og jobbtilfredshet blant fastleger i Bergen Tidsskr Nor Lægeforen 2004; 124: 813-5.

10. Grytten J, Skau I, Sørensen R et al. Legenes arbeidssituasjon etter ett år med fastlegeordningen. Tidsskr Nor Lægeforen 2004; 124: 652-4.

11. Abelsen B, Bæck UDK. Lav stillingsstabilitet som utfordring for fastlegeordningen i Finnmark og Nord-Trøndelag. Rapport nr. 6/2005. Alta: Norut Alta, 2005

12. Warr P, Cook J, Wall T. Scales for the measurement of some work attitudes and aspects of psychological weel-being. J Occup Psychol 1979; 52: 129-48.

13. Diener E, Eunkook M, Lucas R et al. Subjective well-being: three decades of progress. Psychol Bull 1999; 125: 276-302.

14. Den norske legeforening. Legestatistikk. www. legeforeningen.no/index.gan? id $=18 \&$ subid =0\#medlemsstatistikk. (26.5.2008).

Manuskriptet ble mottatt 29.2. 2008 og godkjent 4.11. 2008. Medisinsk redaktør Michael Bretthauer. 